\title{
Germanismos en el Diccionario de Autoridades
}

BEATRIZ GÓMEZ-PABLOS

Universidad Komenského de Bratislava

\section{INTRODUCCIÓN}

La presencia de germanismos en los diccionarios académicos, continúa siendo un tema sobre el que apenas se ha investigado. Sabemos que el Diccionario de Autoridades asentó la base de futuros trabajos y que sobre esa obra se fueron haciendo posteriormente numerosas modificaciones que dieron lugar a las diversas ediciones del diccionario académico. Los errores y omisiones se han revisado y corregido en cada nueva versión.

La influencia de las lenguas germánicas comienza ya en el latín:

Desde el siglo I los germanos comenzaron a alistarse en las legiones; otros se establecían en territorio imperial como tributarios o colonos [...]. Las relaciones sostenidas por los dos pueblos durante los siglos I al IV dieron lugar a un nutrido intercambio de palabras. Los germanos tomaron del latín nomenclatura del comercio, agricultura, industria, vivienda, derecho, etc.; pero también comunicaron a los romanos términos suyos (Lapesa 1981: 112).

La influencia, por tanto, fue recíproca y así como encontramos palabras germánicas en latín, encontramos palabras latinas que también sufrirán cambios fonéticos o semánticos y llegarán a formar parte del acervo germánico. Durante este primer periodo pasan algunos germanismos al latín y de ahí a las respectivas lenguas romances. Encontramos así palabras como guerra, jabón o camisa en francés, italiano y portugués, además de en castellano.

Una segunda etapa comienza a principios del siglo $\mathrm{V}$ con el inminente desmoronamiento del imperio romano y con los desplazamientos de los pueblos germánicos hacia el sur. «En la época de las invasiones fueron muchas las palabras germánicas que entraron en el latín vulgar» (Lapesa 1981: 112). Francos, lombardos y visigodos se asientan en zonas ocupadas anteriormente por los romanos e introducen modos y costumbres, acompañadas de sus respectivas denominaciones. Sin embargo, el número de visigodos que llega a la Península Ibérica no es elevado y pueblan una región no muy extensa, la meseta castellana. A esto se une que las relaciones entre hispanorromanos y visigodos eran escasas hasta finales del siglo VI. Será la conversión del rey Recaredo lo que provoque el acercamiento. La datación de las voces germánicas, así como su recorrido son difíciles de precisar. Unas veces pasan al latín y otras al latín vulgar.

La derrota de Guadalete en el año 711 y la rápida conquista de la península por parte de los musulmanes, cambiaron el rumbo de la historia, también de la historia de la lengua. Por lo que se refiere a los germanismos, podemos hablar de un periodo de paréntesis que 
abarca prácticamente toda la ocupación árabe, es decir hasta 1492. Las pocas voces germánicas que durante la Edad Media llegaron al castellano lo hicieron a través de una lengua romance gracias a contactos culturales, políticos y comerciales entre los diversos reinos vecinos. De este modo, observamos que algunas lenguas romances comparten germanismos por influencia mutua; es decir, una lengua romance actúa de vehículo en la transmisión de voces germánicas. Esto sucede sobre todo con el occitano (v. Gallmischeg 1967).

La política matrimonial de los Reyes Católicos y, en concreto, el casamiento de su hija Juana con Felipe el Hermoso en 1496, abre la tercera etapa en la que hemos dividido la entrada de germanismos y llega, en nuestro estudio, hasta la publicación del Diccionario de Autoridades. Las relaciones mercantiles con Austria y Alemania —además de con los Países Bajos- se estrechan, al igual que las relaciones políticas y culturales. Carlos V será coronado emperador del Sacro Imperio Romano Germánico en 1520 y posteriormente su hermano Fernando, ya en posesión de la corona austriaca. Durante los dos siglos siguientes, los contactos bélicos o pacíficos trajeron consigo nuevos germanismos.

Una vez establecidas las etapas de introducción de germanismos en nuestra lengua, pasamos a analizar lo que el Diccionario de Autoridades entiende por germanismo y los diferentes términos que emplea en los artículos lexicográficos.

\section{DEFINIR GERMANISMO}

Los académicos del siglo XVIII no utilizaban la palabra germánico sino expresiones como Alemán, Godo, Góthico, Tudesco y Teutónico o Theutónico (siempre escritas en mayúscula) y sus formas femeninas, para referirse a la etimología. Veamos algunos ejemplos:

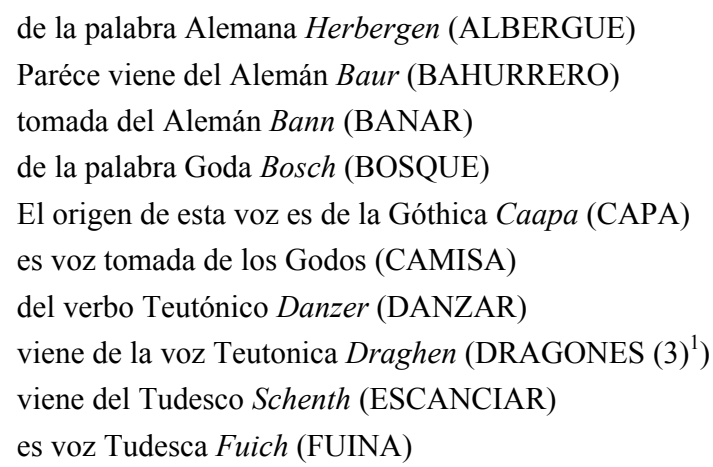

El término que con más frecuencia usan los académicos es alemán; en total treinta y cuatro veces. Los demás (godo, gótico, teutónico y tudesco) aparecen en proporción semejante, entre seis y tres veces cada uno de ellos. Para ser exactos: godo ocho veces (blanco, bosque, capa, daga, danza, feudo, harpa, robar), gótico siete (balcón, bandera, bando, burgo, camisa, perla, escarlata), teutónico cinco (danzar, dragones (3), escaparate, gandaya, tregua), y tudesco ${ }^{2}$ tres (escanciar, fuina, yelmo). Curiosa es la

\footnotetext{
${ }^{1}$ Empleamos el número para indicar la acepción.

${ }^{2}$ Tudesco también aparece en ámbar (2), pero no para referirse a la etimología, sino a los Tudescos, como nación.
} 
expresión «en Lengua Saxonica», de la que solamente hemos encontrado un ejemplo en la tercera acepción de la palabra escote. Además, bajo la entrada banquete leemos que «viene de la voz septentrional Banchet» y al buscar bajo septentrional, será la cita de autor la que proporcione la clave:

SEPTENTRIONAL. Lo que toca, ò pertenece al Septentrión. NAVARRET. Conserv. Disc. 6. Los Godos, Ostrogodos, Alanos, Suevos, y Silingos con las demás Naciones Septentrionáles. M. VILLEG. Hist. de Mosc. lib. 1. cap. 2. Corre este Estado desde la costa del Septentrión, hasta el Océano Septentrionál, ò Mar elado.

Si acudimos al Diccionario para examinar cómo define los términos con los cuales designa los germanismos, observamos que no se recogen ni alemán ni teutónico y que las otras definiciones no hacen alusión a la lengua:

GODO. Voz de la Germanía, que vale lo mismo que Godeño. [rico o principal] GOTHICO. Orden de la Architectura, que introduxeron los Godos [...].

TUDESCO. Lo mismo que Capote segun Covarrubias ${ }^{3}$.

Encontramos una pista en la definición de tudesco que ofrece Sebastián de Covarrubias en su Tesoro de la lengua castellana y que, aunque los académicos no recogen, pudo haberles servido de inspiración:

Tudesco, es lo mesmo que Aleman, porque en lengua Germanica los Alemanes se llaman Doytschen, y de alli Duydescos, corruptamente Tudescos. Otros quieren que se aya dicho el nombre Teuthones, y corruptamente Tudescos [...].

El Diccionario de Autoridades emplea los cinco términos indistintamente como sinónimos. Así en la voz burgo se lee: «lo mas probable es, que es del Alemán o Gothico Burg»; en la voz danza: «de los Godos, que en su Lengua decian Dantza», mientras que en danzar se explica que trae «su origen del verbo Teutónico Danzer». No se percibe, por tanto, diferencia entre alemán y gótico o entre godo y teutónico. La voz perla constata esto mismo: «Es voz Goda [...], nombres, que han quedado en uso de la Lengua Gothica [...]. Los Polácos dicen Perla, los Alemanes Berlen».

Establecer la datación de algunas palabras no es sólo tarea ardua, sino en muchos casos prácticamente imposible. A menudo se trata de hipótesis y aproximaciones, que se van corrigiendo con el paso del tiempo y la llegada de nuevas informaciones. No obstante, nos aventuramos a afirmar que el Diccionario de Autoridades emplea los términos godo, gótico y teutónico para indicar sobre todo aquellos germanismos que entraron a través del latín vulgar, aunque esto se señale expresamente en escasas ocasiones. Véase:

CAMISA. [...] Voz tomada de los Godos; pero lo mas verisimil paréce haverse assi dicho del Latino bárbaro ${ }^{4}$.

FEUDO. [...] Pudo tomarse del Latino Barbaro Feudum; si bien algunos le dan por voz Goda

PERLA. Es voz Goda [...] los Diccionarios dicen viene de Perula de la baxa Latinidad.

TREGUA. [...] voz Theutónica, de donde la tomó la baxa Latinidad.

${ }^{3}$ Covarrubias recoge en la segunda acepción de tudesco: «Un cierto género de capote, dicho assi, por averse traydo el uso del de Alemania».

${ }^{4}$ Los subrayados del artículo son todos nuestros. 
Por otro lado, el término alemán, además de actuar como sinónimo de los anteriores, posee una acepción propia. Alemán es la lengua contemporánea a los académicos, la que se hablaba en el territorio que entonces ocupaba Alemania. Esta acepción contiene una referencia cronológica más moderna, pues se trata sobretodo de germanismos que entran en la tercera etapa descrita arriba. En ese caso, no es sustituible por teutónico o godo, que indican la antigüedad de las voces. Los ejemplos que mejor reflejan este matiz son los neologismos, donde no se admite sustitución:

BRANDIS. [...] Es voz Alemana modernamente introducida.

UVAGUEMAESTRE. [...] Es voz modernamente introducida, y formada de la Alemana Uvag, que significa Carro, Meestor Director, o Xefe.

\section{Baxa Alemania y Alta Alemania}

Antes de continuar, es necesario hacer una observación más sobre los términos alemán y Alemania. Cuando los académicos hablan de Alemania, a veces hacen alusión a la baxa Alemania para referirse a Flandes y los Países Bajos ${ }^{5}$. Véase los siguientes ejemplos:

ALTA. Danza o baile que hasta poco tiempo a parte tuvo mucho uso en España. Covarr. dice la introduxeron los Alemanes de la alta Alemánia, y que por eso se llamó assi a distinción de otra que introduxeron los Flamencos o Alemánes de la baxa Alemánia, que por la misma razón la llamaron la baxa. Lat. saltatio germanica ${ }^{6}$.

BAXA (2). Danza o baile que introduxeron en España los Flamencos o Alemanes de la baxa Alemánia, por cuya razón dice Covarr. se llamó assí, a distinción de otra que introduxeron los Alemanes de la alta Alemánia, que por la misma razón la llamaron la Alta. Saltatio belgica.

FRISA. Tela de lana a modo de bayéta, aunque mas corpulenta, que sirve para aforros y para otros usos. Parece haverse llamado assi porque en lo antiguo se texia en Frisia de Alemania la baxa.

DIQUE. Defensa, o repáro artificioso para detener las aguas, fabricado de varios materiales segun la necessidad. Covarr. quiere que sea voz Árabiga; pero mas cierto es ser Theutónica, pues solo se halla usada en nuestro idioma desde que contratamos con los Paises baxos.

Es difícil establecer la frontera a la hora de analizar la etimología de algunas palabras, pues el flamenco ${ }^{7}$ y el alemán tienen raíz germánica. A esto se añade que haya voces como burgomaestre (Bürgermeister en alemán actual) que, según afirman los académicos, se utilizaba en los dos países:

${ }^{5}$ En la voz flinflón la referencia a Alemania se emplea simplemente para ilustrar la definición. Sin embargo, la traducción latina de flinflón nos proporciona una buena pista de hasta qué punto están unidas la baxa Alemania (Países Bajos o Flandes) con la alta Alemania en la mente de los académicos: FLINFLÓN. El hombre de preferencia abultada, fresco de cara, y rubio, como Alemán u otra Nacion del Norte [...]. Lat. Germanus Flandrius [alemán flamenco!].

${ }^{6}$ Introducimos excepcionalmente la traducción latina por la diferencia que apuntan los académicos en alta y baxa: saltatio germanica, saltatio belgica.

${ }^{7}$ Sobre las voces provenientes del flamenco v. Gómez-Pablos (2014). 
BURGOMAESTRE. El Corregidór de alguna Villa o Ciudád de los Paises de la alta, o la baxa Alemánia. Hállase esta voz muy frecüentemente en las Historias de Flandes, aunque propriamente no es castellana.

\section{AUTORIDADES ETIMOLÓGICAS}

Las voces que el Diccionario de Autoridades declara como germánicas, generalmente recogen una información sobre la etimología. En algunos casos los académicos exponen la opinión de varios autores y se decantan - o no- por la de uno de ellos. En total son 37 las voces que citan una autoridad etimológica ${ }^{8}$. Estos autores son: Sebastián de Covarrubias, Diego de Urrea, Diego de Guadix, el Brocense, Gerónimo Huerta, Juan de Mariana, Bernardo de Aldrete, Isidoro de Sevilla, Jacinto de Ledesma y Mansilla ${ }^{9}$, Ambrosio Morales, Juan Tillet, Gilles Ménage, Bossio y Lypsio ${ }^{10}$. La principal fuente etimológica, como era de esperar, es el Tesoro de la lengua castellana de Sebastián de Covarrubias y esto tanto por el número de voces en que aparece, como por las informaciones de otros autores (Diego de Urrea, Diego de Guadix, el Brocense, Gerónimo Huerta y el P. Mariana) que los académicos reproducen de este lexicógrafo. Así afirma Seco:

En general, las menciones del P. Guadix y de Diego de Urrea, aunque no aparezcan en el Diccionario de autoridades expresamente apadrinadas por Covarrubias, han de tomarse como una referencia tácita a él: es poco probable que los académicos del siglo XVIII tuviesen acceso al manuscrito de Diego de Guadix Recopilación de algunos nombres arábigos (1593), y sobre todo puede darse por seguro que no dispusieron de noticias directas de Diego de Urrea (2003 [1987]: 235).

Esta afirmación se confirma en los germanismos, pues las veces que se cita a Diego de Guadix (albergue, burgo y escarlata) y a Diego de Urrea (albergue) es a través de Covarrubias. También sucede lo mismo con burgo y escarlata, aunque en ese caso los academicos no mencionan a Covarrubias a pesar de haberles proporcionado la etimología germánica:

ALBERGUE. El lugar donde la gente puede recogerse, o se recoge para descanso, abrigo, comodidad, o resguardo de sus personas: y assi se da indiferentemente este nombre a la casa, a la posada o venta, a la choza, o cabaña, concavidad, o cubierto donde los hombres, y tal vez los brutos se retiran para descansar, o se acogen para re-

${ }^{8}$ Algunos de ellos aparecen unas veces como autoridad lexicográfica y otras como autoridad literaria. Por ejemplo, Ambrosio de Morales aparece como autoridad lexicográfica en camisa y como autoridad literaria en estuco. Gerónimo Huerta desempeña el primer papel en ganso y el segundo en fuina. Esto sucede también con Covarrubias aunque no hemos encontrado ningún ejemplo en los germanismos. Así afirma Seco: «el primer Diccionario académico no ofrece autoridades literarias en todos los artículos ni en todas las acepciones. Pero a veces suple esta carencia con autoridades lexicográficas, y es Covarrubias el llamado con más frecuencia a desempeñar ese papel» (2003 [1987]: 227). Seco ofrece una rica muestra de ejemplos.

${ }^{9}$ Religioso dominico, escribió dos libros sobre la lengua primitiva de España. Su nombre no aparece en la lista de autoridades que precede al Diccionario de Autoridades.

${ }^{10}$ Estos cuatro últimos autores son extranjeros. La obra de Jean Du Tillet (150?-1570) que se menciona bajo la voz carlanca, Guerras y tratados de paz, es una obra histórica que trata sobre las guerras francesas de religión. Gilles Ménage (1613-1692) y su obra etimológica, Orígenes de la lengua francesa, son mencionados en el Prólogo del Diccionario de Autoridades. Iustus Lipsius (1547-1606), filólogo y humanista de los Países Bajos escribió una vasta obra en latín. 
pararse y defenderse, especialmente de los malos temporales. El origen de esta voz es dudoso, porque Lypsio, Bossio, y otros la trahen de la palabra Alemana Herbergen, que se extiende a significar hospedería, hospicio, posada, mesón. Covarr. y el P. Guadix dicen que sale del nombre Arabigo Barga, que significa choza, o casa pajiza. Diego de Urrea dice que viene del verbo Arabigo Berége, que vale descansar, aquietarse, recogerse, y juntarse. Pudo tambien formarse de la voz Arabe Berc, que significa lugar de descanso, u hospicio, añadiendo a qualquiera de estas voces el artículo Al.

Albergue, con todo eso, dizen ser nombre arábigo; y el Padre Guadix dize averse dicho alvergue de varga, que en arábigo vale choça o casa pajiza. Pero Diego de Urrea dize valer tanto como lugar de descanso, recogimiento y quietud, del verbo berege, que vale descansar, aquietarse, recogerse, y adunarse. (Covarrubias)

BURGO. Antiguamente se llamaba assi lo que oy se dice Aldea, lugar, alquería o casería; pero en lo moderno se suele tomar por arrabál de Ciudád, o Villa de grande población. El P. Guadix dice que es del Árabigo Burgo, que vale casa pajiza; pero lo mas probable es, que es del Alemán o Gothico Burg, que significa Villa y Lugár.

Burgo, El padre Guadix dize que burgo en arabigo vale casa pagiza, pudiendolo tomar los árabes que vivieron en España de los godos que echaron della [...]. Los godos introduxeron en España y en Italia este nombre, y en Alemania donde hay muchos lugares que acaban en burg. (Covarrubias)

ESCARLATA. Paño y texido de lana, teñido de colór fino carmesí, no tan subido como el de la púrpura o grana. El P. Guadix dice que es nombre Arábigo corrompido de Ixquertál, que significa el mismo colór. El Brocense tiene que es voz Gothica Escurlata, corrompida de Exquisqulliata, y que assi le llamaron tambien los Franceses y Alemanes.

Escarlata, es la color subida y fina del carmesí, o grana fina [...]. El padre Guadix dize ser nombre Arabigo, corrompido de yxquerlat, que significa lo que hemos dicho: y corrompido escarlata: el Frances usa el mesmo vocablo y lo llama Scarlatte, segun el diccionario Galico, Graecco, Latino. El Brocense Escurlata, Godo, Frances y Tudesco, corrumptum ex quisquiliata. (Covarrubias)

Observamos que con el Padre Mariana sucede lo mismo: en un caso se usa a Covarrubias como fuente y aparecen los dos nombres en la misma voz (camisa); en otro, sin embargo, se omite el nombre de Covarrubias, aunque es él la fuente de la que se extrae la opinión del P. Mariana (robar):

CAMISA. La vestidura de lienzo, fabricada regularmente de lino, que se pone en el cuerpo inmediata a la carne, y sobre la qual assientan los demas vestidos. Suele hacerse tambien de lienzo de cáñamo, como lo usan los rústicos: y aludiendo a esto, dice Covarr. que algunos son de sentir se dixo Camisa de Cañamisa, por haver sido priméro el uso del cáñamo que el del líno. El P. Mariana, y Ambrósio de Moráles sienten que es voz tomada de los Godos; pero lo mas verisimil paréce haverse assi dicho del Latino bárbaro Camisia segun afirma San Isidoro.

Camisa, la vestidura de lienço que el hombre trae debaxo de las demas ropa, a rayz de las carnes, el padre Mariana en su historia de España, cuenta entre otros nombres camisa, y dize ser tomado de los Godos. San Isidoro, lib. 19 cap. 22 camisias vocamus [...]. (Covarrubias)

ROBAR. Quitar o tomar para si, con violencia o con fuerza, lo ajeno. Viene del Latino Rapere. El P. Mariana en su História de Esp. lib. 5. cap. I cuenta esta voz entre los nombres tomados de los Godos. 
Robar, [...] El Padre Mariana en su Compendio historial lib. 5. cap. I. cuenta entre los nombres tomados de los Godos esta palabra robar. (Covarrubias)

También el Brocense (escarlata, véase arriba) y Gerónimo Huerta (fuina) son citados a través de Covarrubias:

FUINA. Especie de marta o rapósa del tamaño de un gato, de colór rubio que tira algo a negro, y por la barríga blanca. Es mui dañina y destruidora de los gallinéros y palomáres. Covarr. dice es voz Tudesca Fuich, que significa Rapósa; pero Huerta sobre Plinio lib. 8 cap. 55 dice sale del nombre Francés, que significa la Haya, por criarse este animál regularmente en ellas.

Fuina, es una especie de marta, o raposilla mui dañina [...]. En realidad de verdad el nombre es Tudesco; porque en la lengua Alemana llaman a la raposa fuich: y de alli se dijo fuichna y fuina, raposilla. El Licenciado Geronimo de Huerta en el comento sobre Plinio libro 8 capitulo 55. fol. 302b dize ser la fuina una especie de marta no fina, y que por razón de criarse en las hayas se dixo assi, que en lengua Francesa Fau, vale haya. Refiero lo que dize, cada uno escogera lo que mas le quadrare. (Covarrubias)

No obstante, al comparar las voces balcón, bando, banquete y blanco en Autoridades y el Tesoro, observamos que aunque en ellas se mencionan conjuntamente a Aldrete y Covarrubias, los académicos han acudido al primero directamente ${ }^{11}$.

BALCON. Cierto género de corredor pequeño, que sale voleado de la pared de las casas, rodeado de balaustres hechos ordinariamente de hierro, y tal vez de piedra ò madéra, y sirve para assomarse y vér lo que passa. Covarr. siente que es voz Italiana; pero Aldrete afirma que el orígen es del nombre Góthico Balck, que significa esto mismo.

Balcon, es nombre Italiano, vale ventana volada, encima d ela puerta de la fortaleça, quiasi bolcone, seu bolcone. Es nombre Veneciano, y de que usan los Ginoveses. Tomase por ventana rasgada preeminente, y de Magestad.

BANDO. Edicto, ley o mandato solemnemente publicado de orden superiór: y la solemnidad y acto de publicarse se llama tambien assi. Covarr. dice que es voz Toscána; pero Aldrete afirma que es Góthica Band, que significa lo mismo.

Bando, nombre Toscano, el pregon que se da, llamando algun delinquente que se ha ausentado, y de aqui se dixeron bandidos, y bandoleros, comunmente vandoleros, por estar echando vando y pregón contra ellos en la republica. (Covarrubias)

BANQUETE. Comída, merienda ò cena espléndida regalada y abundante, de mucho aparáto y diversidád de manjáres, en que concurren muchos convidados. Aldrete y otros concuerdan en que viene de la voz septentrional Banchet, que significa lo mismo. Covarr. dice que sale de las bancas ò mesas sobre que se ponen las viandas.

Banquete, vale tanto como un festin conbite, y comida esplendida, abundante de manjares, y rica en aparato. Tomó nombre de las bancas, o mesas sobre que se ponen las viandas [...]. Dizen ser vocablo Septentrional Banchet.

BLANCO. Aquél color que recibe mas de la luz: como la nieve, la leche y otras cosas. Aldrete en el cap. 15 del lib. 3 del Orígen de la léngua Castellana y Cova-

\footnotetext{
${ }^{11}$ Lo mismo se comprueba en la voces perla y danza.
} 
rrubias en su Thesoro conviénen en que esta voz es Goda septentrional, por llamarse Blanch en aquel idióma, lo mismo que nosotros decimos blanco.

Blanca, [...] Blanco es nombre Godo Septentrional. Blanch. (Covarrubias)

Si examinamos el número de veces que se cita a Covarrubias y las veces en que son citados otros autores, constatamos que la desproporción es bastante grande. Seis autores son recogidos sólo en una voz: Lysio (albergue), Bossio (albergue), Ambrosio de Morales (camisa), Juan Tillet (carlanca), Jacinto de Ledesma y Mansilla (perla) y Ménage (harpa $)^{12}$. Isidoro de Sevilla llega a las dos voces (camisa, perla) y Aldrete a un total de nueve (balcón, bandera, bando, banquete, blanco, daga, danza, harpa y perla). Lo cual no significa que siempre sean partidarios - como tampoco Sebastián de Covarrubias- de la etimología germánica. Traemos a colación las voces en que aparecen estos autores y que no se han citado hasta aquí:

BANDERA. Insígnia militar de que ordinariamente usan los Regimientos de Infantería: la qual es un pedazo de tafetán de dos varas poco mas ò menos en quadro de vários colóres segun el de cada Nación, con sus armas y divísas, el qual está puesto en una media pica ò espontón, y le lleva uno de los Alféreces, siendo el lugar donde se colóca el centro del batallón. Es voz Góthica formada de las palabras Ain baner, segun afirma Aldrete, lib. 3. cap. 14. del orígen de la lengua Castellana.

BARÓN. Dignidád y dictado a manéra del de Marqués, Conde, etc. Covarr. dice que es nombre Francés, en donde el que lo ha de ser segun sus leyes ha de tener tres lugáres, y que algúnos afirman ser Alemán: y añade que puede venir del verbo Griego Barein, que vale gravem esse, $\mathrm{u}$ del Hebréo Bara creare, $\mathrm{u}$ del verbo Barah eligere.

BOSQUE. Sitio montuoso lleno de árboles y matas espessas, o un grande pedázo de tierra lleno de árboles, que cortados suelen servir para los edificios y otros usos, y donde suelen criarse Venádos y otros animales de caza. Covarr. dedúce esta voz del Francés Bois, que vale palo, o madéra, u del Griego Bosco, que es Apacentar; pero parece mas verisimil la tomassemos de la palabra Goda Bosch, que es la misma, suavizada la terminación. Los Flamencos llaman a la selva con esta misma terminación.

CARLANCA. Collar ancho con puntas de hierro puestas hácia fuera, para armar el pescuezo de los mastínes contra las mordeduras de los lobos, el qual suele hacerse de hierro, o cuero muy fuerte. Su etymología puede ser del sonido que hace el perro quando jadéa, estando cansado con la lengua defuera: aunque paréce mas verisimil salga de la palabra Alemána Carcan, que vale Collar, segun Juan Tillet en la prefación de las Guerras y tratados de paz, tom. 2. fol. 136.

DAGA. Arma blanca, corta y con filos a ambas partes, por lo menos hácia la punta, que tiene agúda. Háilas tambien quadradas y de un filo. Tiene guarnición menor que la espada, con que cubre el puño, y gavilanes para los quites. Aldrete dice es uno de los nombres que nos quedaron de los Godos, en cuya propria Lengua se llamaba Dage, o Dagon.

DANZA. Báile sério en que a compás de instrumentos se mueve el cuerpo, formando con las mudanzas de sitio vistosas y agradables plantas. Aldrete pone este nombre entre aquellos que nos han quedado de los Godos, que en su Lengua decian Dantza.

${ }^{12}$ Ménage defiende en perla la etimología latina, mientras que en harpa propone ambas, la latina 
DANZAR. Bailar con gravedád a compás de instrumento, con orden, escuela y enseñanza de preceptos. Covarr. dice viene del Latino Ducere, porque en las danzas hai siempre uno que guia a los otros; pero parece mas verisimil trahiga su origen del verbo Teutónico Danzer, que vale lo mismo.

ESCANCIAR. Echar el vino de un vaso a otro, ministrarle y echarle en las mesas y convites. Covarr. dice que este verbo puede venir del antiguo Conglare, y de aqui Congiar, y Canciar, mudada la g en c por razón del nombre Congio, que es cierta medida de vino: $\mathrm{u}$ del verbo Toscano Cangiare, que vale trocar y echar de una parte a otra. Algunos dicen que es voz Arábiga formada de Cancia, que es un género de vaso entre los Arabes, y otros son de opinion que viene del Tudesco Schenth, que significa el Copéro ${ }^{13}$.

ESMALTE. Cierta labór de diversas colóres, que se hace ordinariamente sobre oro u plata sobredorada. Es obra de gran primór, y su matéria tiene principio en el Arte de la Alchimia. Covarr. sospecha que el origen desta voz sea Theutónico, por haver venido esta invencion de las partes Septentrionales. Y tambien discurre que pudo derivarse del Griego Malthe, que es una matéria durissima fabricada con cal viva, y gordúra o manteca de puerco.

ESTOQUE. Espada angosta y de quatro esquinas, que por lo regular suele ser de mas de marca, y se juega siempre de punta. Covarr. dice que viene del Italiano Steco, que significa Vara que termina en punta; pero es mas verisimil se haya tomado de la voz Alemana Stechem, que vale Estocada.

ESTUCHE. Caxa pequeña, donde se trahen las herramientas de tixéras, punzón, cuchillo y otras piezas. El origen desta palabra parece Alemán. Los Vizcaínos ${ }^{14}$ dicen que es Vascuence, y que significa cosa apretada. Covarr. discurre que sale del Griego Theca, y corrompida la voz Tuche, y de aqui Estúche.

ESTUFA. Aposento recogido y abrigado, al qual se le da calór artificiosamente con fuego por la parte exteriór. Covarr. dice que viene del nombre Latino Aeslus, que vale calór, pero lo cierto es que es voz Alemana, donde son mui usadas las estúfas, como tambien en los Países baxos, por ser tierras mui frias.

FERRERUELO. Carpa algo larga, con solo cuello, sin capilla. Covarr. dice tomó el nombre de cierta gente de Alemánia, que llaman Herreruelos, por haver sido los priméros que usaron esta especie de capa.

GRIS. Colór obscúro entre azúl y pardo. Covarr. siente es voz Flamenca o Alemána, y que sale del verbo Griisen, que significa Llorar, porque los que lloran sus difuntos se visten deste colór.

HARPA. Instrumento Músico de figura casi triangular, cuyo cuerpo es compuesto de un número de costillas de madera, formando una manera de ataúd, que se une por encima con una tabla delgada, hechos en ella algunos agujeros grandes para que salga la voz, y en el medio otros agujeros chicos, donde se afianzan las cuerdas con unos botoncillos, las quales ván a parar a la cabeza que está unida a lo más es-

${ }^{13}$ Excepto danza y danzar, no recogemos los derivados de otras voces germánicas, si no contienen información etimológica. En el Diccionario de Autoridades encontramos escancia y escanciador, pero sin alusión a la etimología; y lo mismo sucede con los derivados de estaca. Hemos seguido el mismo procedimiento con las acepciones de una misma voz: hemos recogido sólo aquella donde aparece la etimología germánica.

${ }^{14}$ También aquí la fuente de las etimologías proviene de Covarrubias. En la voz estuche se lee en el Tesoro de la lengua castellana: «caxa pequeña donde se traen las herramientas de tixeras, cuchillon, punçon y las demas pieças [...]. Algunos piensan ser nombre Tudesco: los Vizcainos, dizen, que es vocablo Vascuence, yo pienso derivarse del nombre Lat. theca, y de alli thuque, stuche, Graece». 
trecho del cuerpo [...]. El P. Mariana dice es palabra Goda, y lo mismo Aldrete. Covarrubias dice es Griega, de un verbo que significa Arrebatar, y Menage dice viene del Latín Harpa, o del Alemán Herp, o Harpff.

JARDÍN. Huerto de recreación, compuesto de diversas flores y hierbas olorosas, ordenado regularmente en varios quadros, y en ellos lazos y labores, formadas de las mismas hierbas. Covarr. le dá varias etymologías, y se inclina a que es nombre Alemán.

LACAYO. El criado de escaléra abaxo y de libréa, cuyo exercicio es seguir a su amo, quando va a pié, acaballo o en coche. Covarr. siente es voz Alemána, que se introduxo en España en tiempo del Rey Don Phelipe Primero; pero tambien es verisimil se puede haver tomado del Francés Laquai, que significa lo mismo.

PERLA. Substancia dura, clara y lucida, que se cria en las conchas de las ostras, y regularmente se forma en figura redonda, $\mathrm{u}$ de una perilla. Las mejores son las Orientales, las mas lisas y redondas. Es voz Goda, segun siente Aldrete en su Origen de la Lengua Castellana: y el P. Fr. Jacinto de Ledesma y Mansilla, en la Lengua primitiva de España, lib. 2 cap. 4 en la lista que pone en los nombres, que han quedado en uso de la Lengua Gothica: y es una congruencia eficacissima el mantenerse en las Provincias Septentrionales este mismo nombre, o con pequeña inflexión. Los Polácos dicen Perla, los Alemanes Berlen, en la Italia Perla, los Franceses Perle. Menage y comunmente los Diccionarios dicen viene de Perula de la baxa Latinidad, la qual tomó sus voces de las Naciones dominantes. Otros sienten con Plinio ${ }^{15}$, que viene del Latino Perna, que significa la concha en que se crian: y finalmente otros del Latin Pyrum, o Pyrula, por la figura que suelen tener de perillas; y entre estos S. Isidoro, por semejanza a la extremidad redonda de la raíz que llama Pyrula. Y aunque todas estas etymologías son verisimiles las mas, cierta es la priméra.

RICO. Noble u de alto lináge, u de conocida y estimable bondád. Covarr. dice que es voz Goda, y viene de la voz Ric, que vale Señor.

ROCÍN. El caballo de mala traza y flaco. Covarr. dice viene del Alemán Roslin.

TONEL. Cubeta, o candiota, en que se echa el vino, u otro liquór, para llevarle de una parte a otra, especialmente el que se embarca. Covarr. quiere se derive de la palabra Tunél, por embasarse en él los atunes, que se trahen a vender; pero es mas natural venga del Aleman Tonne, que significa vasija de vino.

Covarrubias participa, además, en la discusión de otras voces germánicas, sin que los académicos mencionen su nombre. Basta acudir al Tesoro para verificarlo:

FEUDO. Especie particular de contrato [...]. Pudo tomarse del Latino barbaro Feudum; si bien algunos le dan por voz Goda, o formada del nombre Fé.

Feudo, es nombre Godo, que entre los Latinos se tiene por barbaro [...]. Verissimil es, averse dicho feudo de fee. (Covarrubias)

ESTACA. Palo fuerte, que por una parte es puntiagúdo, para poderlo hincar en la tierra, o en el carro, o en otra cosa. El origen desta palabra parece que viene del Alemán Stach, que assi llaman al bastón o palo rollizo ${ }^{16}$.

Estaca, un palo recio, que por una parte esta puntiagudo para hincarse en la tierra, o en el carro o otra parte. (Covarrubias)

\footnotetext{
${ }^{15}$ De todos los autores que se recogen en esta voz, Covarrubias únicamente cita a Plinio

${ }^{16}$ Los académicos unen las voces estaca y estacas de Covarrubias.
} 
Estacas, como unos clavos de hierro muy grandes para las vigas. El Aleman llama al baston, o palo rollizo, stach. (Covarrubias)

ESTUCO. Cierta mezcla de cal, y yesso, aréna y marmol molido con una temperatúra tal que no se pega a la ropa, y queda tan lustrosa en la paréd, que parece de alabastro despues de pulido. Hacense de ellas estatuas y otras obras mui primorosas. El origen es Alemán Stuch.

Estuque, una cierta mezcla de cal, yeso y arena de marmol molido con una temperatura tal, que no se pega a la ropa, y queda tan lustrosa en la pared, que parace alabastro con pulimento [...]. El nombre deve ser Aleman, o Flamenco, stuch. (Covarrubias)

GANSO. Ave doméstica y mui conocida. Es del tamaño de un Aguila: tiene el pico ancho y encarnado, con unos dientecillos como de Sierra: las piernas cortas, escamádas y roxas, y los dedos de los pies unidos con una telilla, de que se sirve para nadar, porque vive frequentemente en el agua. Hailos de diversas colóres. Algunos quieren se derive esta voz del Alemán Ganzo, que significa Ansar pequeño; pero parece mas natural se haya formado anteponiendo una G al Latino Anser ${ }^{17}$.

Ganso, ave conocida [...]. Dixose ganso quasi anso, del nombre Latino anser añadiendole la g al principio, aunque segun Plinio lib. 10 cap. 22 Ganso se pudo dezir quasi ganzo palabra Alemana que significa el anser pequeño, y dize ansi hablando de los gansos de Germania. (Covarrubias)

MARISCAL. Oficial mui preeminente y principal en la Milicia, inferior solamente al Condestáble. Era Juez de todo el Exército y le tocaba, no solo castigar los delítos, sino tambien el gobierno economico, disponiendo los alojamientos, haciendo labrar puentes, previniendo los abastos, y corrigiendo las medidas, y otras cosas semejantes. Oy se conserva este título en las Casas que descienden de los que fueron en lo antiguo de los Reinos de Castilla, Andalucía, etc. El origen desta voz puede venir del Alemán March o Marach, que significa Caballo, y de Scalch, que vale Maestro.

Mariscal, el nombre Mariscal dizen ser Tudesco, y recibido en Francia, corrompido de Marisal, que vale justicia de la Corte y casa Imperial. (Covarrubias)

Queda añadir que las discusiones etimológicas no siempre tienen un autor concreto:

ESCOTE (3). Vale tambien la cantidad y parte que proráta cabe a cada uno de los que se han divertido o comido en compañia, por razon del coste y gasto hecho. El origen desta voz en este significado quieren algunos que venga de $S c o t$, que en Lengua Saxonica vale impuesto o tribúto. Otros le deducen del Toscano Scotto, que significa comida hecha a pasto, y otros dicen que sale de los nombres Latinos Esca y Quotus, y que sincopados se formó Escóte.

\section{ETIMOLOGÍAS SIN AUTORIDAD LEXICOGRÁFICA}

En el Diccionario de Autoridades aparecen también voces en las que no se menciona ninguna autoridad lexicográfica; papel que pasa a desempeñar la misma Academia. Se trata en total de 23 voces con algunas características comunes:

a) llevan una cita literaria (excepto: brandemburg, brandis y paquete);

\footnotetext{
${ }^{17}$ La primera cita literaria en esta voz está extraída de Covarrubias: «Huert. Plin. lib. 10 cap. 22 Al que llamamos en España Ansar, Pato, o Ganso, llamaron los Arábigos Avaz».
} 
b) recogen un equivalente en alemán (excepto: brandis, escaparate, tregua y brindis; este último no lo recoge porque aparece ya en brindar);

c) los académicos afirman con certeza su origen germánico empleando para ello expresiones como: «tomada del Alemán», «Es voz Alemana», «Trahe su orígen esta palabra del Alemán», «El origen de esta voz es Teutónico», «Es voz derivada del Tudesco», etc. Solo en cinco casos manifiesta inseguridad con expresiones como: «Paréce viene del Alemán», «Su etymología paréce Alemána», «parece viene de la voz Teuthonica» (v. bahurrero, bibero, gandaya, marqués y trabuco).

Aquí va el elenco de voces que la Academia considera de origen germánico, sin el apoyo de otra autoridad lexicográfica:

BAHURRERO. Cazadór de paxarillos con lazo, liga, o red. Paréce viene del Alemán Baur, que vale Agreste rústico, por estar de ordinário en el campo los que tienen este exercicio. Es voz antiquada de Aragón.

BANAR. Señor de vassallos con autoridád de poderlos alistar debaxo de su própria bandéra. Es voz antiquada de Aragón y tomada del Alemán Bann, que significa jurisdicción y dominio.

BÍBARO. Animál amphibio, que segun Lagúna es lo mismo que Castór. Vease Castór. Su etymología paréce Alemána del nombre Biber, pues los Franceses le llaman tambien Bieure ${ }^{18}$.

BIRRETE. Espécie de bonéte de várias formas, segun los usos. A los principios eran comunmente colorados o roxos. Es tomado del Alemán Birret.

BRANDEMBURG ${ }^{19}$. Casáca grande o sobretódo, ancho y capaz de poderse solapar, y doblar delante del pecho, con unas mangas anchas y largas, con una abertúra para poder sacar los brazos quando fuere menester. Fué invención del elector de Brandemburg, para el abrigo de los soldádos de Infanteria, y de ahí tomo el nombre, y se difundió a otras Naciones y Persónas por su comodidád.

BRANDIS. (Brandís) Casacón grande, que se pone y viste sobre la casaca para el abrigo, y que solápa sobre el pecho, y se trahe algunas veces abierto, y otras cerrado, y atacado con unos botones. Es voz Alemana modernamente introducida.

BRECHA. La rotúra, o abertúra hecha en la muralla o paréd fuerte con las piezas de artillería, o con otros ingénios, o instrumentos bélicos. Trahe su orígen esta palabra del Alemán Brechen, que vale lo mismo.

BRINDAR. Convidar, y en cierta manera provocar a uno para que beba, al mismo tiempo que el vá a beber. Viene este verbo del Alemán Bringuen, que significa provocar, y regularmente se hace juntando la expressión de a la salud de V.m. a la salud de Fuláno, etc.

\footnotetext{
${ }^{18}$ Aunque en general hemos renunciado a transcribir las citas literarias para no recargar demasiado el texto, vemos que aquí actúa a la vez como autoridad lexicográfica y literaria. «Lag. Diosc. lib. 2. cap. 23. El animál en Latin se dice Castór, y Fiber, en Castellano Bibaro, Francés Bieure, Tudesco Biber».

${ }^{19}$ El grupo consonántico $r g$ a final de palabra resulta extraño a nuestra morfología. Así burg y chamberg pasan a burgo y chamberga, lo cual no sucede en brandemburg.
} 
BRINDIS $^{20}$. La provocación, convíte, o instáncia que se hace a otro para beber, en la forma que se dice en el verbo Brindar.

CAPA. Vestidura hecha de paño u de otro género de lana y tambien de seda, que se pone sobre los hombros y llega hasta las rodillas, suelta y en forma redonda, y sirve para cubrir al hombre o abrigarle: por lo qual se pone sobre todos los demás vestídos y para adorno y seguridad tiene por la parte superior uno como cuello, o pedazo de la misma tela que se llama Capilla, que cae por detrás y ciñe los hombros. El origen de esta voz es de la Góthica Caapa, que significa lo mismo.

CHAMBERGA. Casáca ancha, cuya longitud passaba de las rodillas: su aforro volvía sobre la tela de que era la casaca, con una faxa de quatro a seis dedos de ancho de arriba abaxo por ambos lados: las mangas algo mas anchas de lo que se usan ahora, y mas cortas, tambien con una vuelta del mismo aforro. Diósele este nombre por haver trahido este trage con sus Tropas el Mariscal de Chamberg, quando vino de Francia a la guerra de Portugal.

CHAMBERGA (2). Se llamó también a un Regimiento, que se formó en Madrid en la menór edad del Rey Don Carlos II gobernando los Réinos la Reina Doña Mariana de Austria su madre, para su guarda: del qual, en su priméra formacion fué Coronél el Rey, y después el Marqués de Aitóna, y últimamente Don Fernando Miguél de Tejáda. Hallaronse inconvenientes para que subsistiesse, por cuya razón se envió a Cataluña, sin otra exencion, ni distincion, que la que tenia otro qualquier Tercio ordinário, adonde por último se reformó. En su primera creación entraron por Capitánes muchos Grandes de España y otros Oficiales de graduación y crédito. Tenía su Quartél en Madrid en la calle de la Palóma: y los Oficiales, quando entraban de guardia en Palácio, se ponian unos capotillos de la hechúra de los que se ponen los Reyes de Armas en sus funciones públicas. Diósele este nombre porque trahían los Oficiales y soldádos las casacas como las chambergas.

DRAGONES (3). Se llaman en la Milicia cierta classe de Soldádos, que aunque ván montados tienen obligación de desmontarse y pelear a pie como la Infanteria quando se les mandáre, por lo qual no calzan botas fuertes como los Soldádos de acaballo, sino otras más ligéras, sin lo que corresponde al pié, para poderse menear sin embarazo. La raíz deste término viene de la voz Teutonica Draghen, que vale caminar montado.

ESCAPARATE. Alhája hecha a manéra de alhacéna o almário, con sus puertas y andénes dentro, para guardar buxerías, barros finos y otras cosas delicadas, de que usan mucho las mugéres en sus salas de estrádo para guardar sus dixes. El origen de esta voz es Teutónico.

FUCAR. El hombre rico, hacendado, y que tiene grandes conveniencias. Tomóse la voz de los Condes Fúcares Alemanes, que adquirieron mucho caudal ${ }^{21}$.

GANDAYA. Ociosidad y bribonería. El origen de esta voz parece viene de la voz Teuthonica Gangajes, que significa Dia de fiesta.

MARQUÉS. Dignidad, ditádo o título mui honorífico, que crean los Príncipes soberanos en sus Domínios, para premiar y remunerar con él los servicios y méritos de sus principales vasallos. La etymología desta voz es mui controvertida entre los

\footnotetext{
${ }^{20}$ En esta lista de voces, hemos recogido excepcionalmente brindis y chamberga, aunque no contienen información etimológica.

${ }^{21}$ Los académicos se refieren a la familia de banqueros y negociantes alemanes Fugger, prestamistas de los reyes Carlos V y Felipe II. La grafía se corregirá en la edición de 1899 del DRAE.
} 
Autores; pero la mas verisimil parece haberse tomado de la voz Alemana Marchgraph, que significa Capitán de Frontéra.

PAQUETE (2). Se llama comunmente el conjunto u mazo de cartas, unido y cerrado en forma de pliego. Dixose del Aleman Pak, que significa lo mismo.

TALCO. Especie de piedra blanca, clara, y transparente, que se divide en delgadas hojas. De él hai dos especies, uno que se cria en Venecia, el qual es blanco, rugoso al tacto: el color es plateado, y resplandeciente. Otro se cria en Moscovia, que es mas duro, aunque pulido, y suave al tacto, y casi tan transparente como el vidreo, y en su lugar sirve para las linternas, quadros, y otros usos. Es tomado del Alemán Talc, que significa esto mismo.

TRABUCO. Máchina bélica, que se usaba antes de la pólvóra, y artilleria, y con ella se arrojaban piedras mui gruessas con mucho impetu, como ahora la pieza de cañon. Puede venir del Aleman Tribuck, que significa lo mismo.

TREGUA. Suspension de armas, cessacion de hostilidades por determinado tiempo entre los enemigos, que tienen rota, o pendiente la guerra. Es voz Theutónica, de donde la tomó la baxa Latinidad.

UVAGUEMAESTRE. Oficial Militar, que cuida de dar providencia en el exército, para la seguridad, y forma de marchar los equipages. Es voz modernamente introducida, y formada de la Alemana Uvag, que significa Carro, Meestor Director, o Xefe.

VIVAC. Guarda, que se hace de noche para la seguridad de una Plaza, o un Exército, quando está cerca del enemigo, y expuesto a ser assaltado. Componese de un cuerpo de Soldados de Infanteria, o Dragones, quando sirven apie con los Oficiales correspondientes. Es voz tomada del Francés Bivovac, que significa lo mismo; y aunque el Francés escribe esta voz von b, respecto de ser tomada del Aleman Vveyvvach, que significa Guarda doble, se debe fijar con v.

YELMO. Parte las armas antiguas, que los Caballeros usaban en las batallas, justas, y tornéos, y oy sirve de ornato en los escudos de armas, y se componia de varias piezas de acero con sus muelles, y goznes, y servía para defender toda la cabeza, y cara con una pieza, que llamaban visera, compuesta de una rexilla del mismo acero, con la qual dexaban libre la vista, y en esto se distinguia del morrión, celada, y capacete, de que usaba la Infantería. Es voz derivada del Tudesco Helm, que los Italianos dixeron Helmo, y nosotros Yelmo.

Es curioso que entre los germanismos encontremos dos voces marcadas como regionalismos aragoneses y que además en los dos casos se consideren anticuadas ( $b a h u$ rrero y banar).

Observamos también que en dos voces (vivac y chamberga) se hace referencia al francés, indicando así el camino por el que llegaron a nuestra lengua. En el caso de vivac los académicos corrigen la grafía francesa remitiendo a la palabra original alemana. La doble uve alemana se simplifica a v, por carecer el castellano de esa letra. No sucede lo mismo con uvaguemaestre, donde advertimos que la doble uve original se ha transcrito como $u v$, vocalizando así la primera letra. En el caso de chamberga, los académicos nombran al Mariscal de Chamberg —en realidad Schomberg (1616-1690), transcrito a la francesa ${ }^{22}$. La guerra a la que se hace aquí referencia es la de 1661 que terminará en 1665 con la Vic-

${ }^{22}$ En 1780 se recoge la casaca, el sombrero, el regimiento y el soldado, pero no hay alusión al mariscal Schomberg. La grafía Chamberg se corrige a Schomberg en la edición de 1884 del DRAE. 
toria de Montes Claros. Tras sucesivos enfrentemientos, se firmará el Tratado de Lisboa en 1668, donde Portugal recupera por fin su independencia. Por la relativa cercanía a la edición del Diccionario de Autoridades, se puede afirmar que se trata de un neologismo. Al mismo tiempo, al ser una prenda de vestir queda sujeta a la fugacidad de la moda, como también se aprecia en la definición: «las mangas algo mas anchas de lo que se usan ahora, y mas cortas». Tanto éxito tuvo, sin embargo, esta casaca, que la voz chamberga se utilizó para designar por extensión a un regimiento, cuyos soldados llevaban dicha pren$\mathrm{da}^{23}$. El regimiento se creó durante la regencia de Mariana de Austria — de 1665, año en que fallece su esposo Felipe IV, hasta 1675, año en que su hijo Carlos II es declarado mayor de edad y asume el gobierno. En esta acepción también puede ser considerada como un neologismo por su cercanía cronológica al Diccionario de Autoridades.

En el elenco de voces que la Academia recoge como germánicas, marca sólo dos de ellas como neologismos: uvaguemaestre y brandis. Aunque ni la omisión de cita literaria ni la datación tardía de la cita literaria sean garantía para afirmar que tenemos entre manos un neologismo, pensamos que es justificado añadir chamberga ${ }^{24}$ (en sus dos acepciones) y brandemburg $^{25}$; esta última contemporánea a las anteriores. Es muy probable que el «elector de Brandemburg» al que se refieren los académicos, sea Federico Guillermo I (1620-1688), que recibió el título de Gran Elector de Brandeburgo. Este personaje que anexionó tierras para Prusia, reconstruyó y consolidó el país después de la guerra de los treinta años, bien puede ser el inventor de la prenda que describe el diccionario académico.

Deseamos hacer una última observación sobre la etimología de paquete. A pesar de que se observa una tendencia general en el diccionario a recoger el origen de las palabras en la primera acepción y a no repetirlo en las siguientes, hay algunas pocas en las que se recoge en acepciones posteriores (por ejemplo la tercera en dragones, o la segunda en paquete). Sorprende, sin embargo, que el Diccionario de Autoridades atribuya etimología germánica a paquete, y etimología inglesa a la voz paquebot ${ }^{26}$, cuando sabemos que en alemán existe también la palabra Boot para designar embarcación ${ }^{27}$.

\section{GERMANISMOS LATINOS O LATINISMOS GERMÁNICOS}

En un sentido más amplio y formando un grupo aparte, se podrían entender por germanismos aquellas voces que llegan al castellano a través del alemán, aunque su origen sea latino. Véase áulico, dieta (2), elector - junto con sus derivados-, y palatina. En todos estos casos son palabras relacionadas con la Corte Imperial Alemana:

\footnotetext{
${ }^{23}$ El derivado chambergo designa al soldado u oficial, como también al sombrero y otras cosas que utiliza. El sombrero ha conocido numerosos cambios y sigue siendo utilizado hasta hoy como parte del atuendo campesino en el norte de Argentina.

${ }^{24}$ En brandemburg falta la cita literaria; en chamberga la cita es de 1680 (Pragmática de Tassas); la segunda acepción de chamberga no contiene cita.

${ }^{25}$ Como se puede apreciar, varios de estos neologismos están asociados a la moda militar.

${ }^{26}$ Autoridades lo define como: «Embarcacion que sirve para llevar los corréos de una parte a otra. Es voz Inglesa».

${ }^{27} \mathrm{Ni}$ paquete ni paquebot recogen cita literaria.
} 
ÁULICO. Lo mismo que Cortesáno y Palaciégo: y assi se dice Conséjo áulico, Consejéro áulico. Este renombre está con propriedád tomado en Alemánia en la Corte Imperiál; pero el uso le ha extendido a lo que pertenéce a los Cortesános y Palácios de los Reyes y Príncipes Soberános. Es voz puramente latina.

DIETA. (2) La assamblea, junta o congresso de los Estádos o Círculos del Império Grande de Alemánia, hecha para deliberar sobre los negócios públicos, Políticos u de Religión. En este sentido es la misma voz Latina, que significa la Sala en que los Antiguos celebraban sus banquétes: y como era costumbre de los Alemánes tratar en la mesa los mayóres negócios, de esto se les dió el nombre de Dietas o Senáculos a sus Congressos Políticos. Después se ha extendido a significar las Cortes de Polónia y las Assambleas de los Cantónes Suizos, que llaman Diétas generáles.

ELECTORES DEL IMPERIO. Son ciertos Príncipes de Alemánia, a quienes toca unicamente la elección y el nombramiento del Emperador.

ELECTORADO. Ciertos Estádos en Alemania, a cuyos Príncipes posseedores está anexo el derecho de elegir Emperadór: como el Arzobispo de Maguncia, el de Colonia, el Ducado de Saxonia, Marquesado de Brandemburg, etc.

ELECTORADO. Lo que pertenece a la dignidad de Electór: como Príncipe electorál, Dignidád electorál, etc.

ELECTRIZ. La mugér del Príncipe seculár que es electór: como la del Conde Palatino del Rhin, la del Duque de Saxonia, etc.

PALATINA. Adorno de que usan las mugéres para cubrir la garganta y cuello en invierno, al modo de una corbata tendida: hacese de martas, seda, plumas, etc. Diósele este nombre por haber sido su inventora una Señora de la Corte del Electór Palatino.

\section{LA PRESENCIA DE ALEMANIA}

Las alusiones a Alemania no son siempre etimológicas. En algunas definiciones, encontramos otro tipo de información relacionada con Alemania. Véase por ejemplo:

ALEMANISCO. cosa perteneciente a Alemania, de cuyo nombre está formada esta palabra: la qual en el uso de nuestra léngua se aprópia a cierto género de mantelería fabricada y texida a quadraditos, algo mayores que la que se llama de gusanillo: y porque este texido vino la primera vez de Alemánia, se le dió el epitheto de Alemanisco.

ÁMBAR (2). son varias las opiniones de qué género, o especie sea el que comunmente se llama ámbar, de que se hacen Rosários, Imágenes y otras cosas. Unos quieren que sea goma de unos álamos que se crían en los Países Septentrionales, otros betún que se congela como el crystál, otros minerál; pero según lo que el Doctor Laguna en el lib. I. cap. 90 sobre Dioscórides dice como testigo de vista, no queda razón de dudar, que es lo siguiente. Mas lo que yo he podido alcanzar y puedo afirmar como testigo de vista acerca del ámbar, es que en la costa del Océano Germánico en la región de Prúsia, o Borusia, colocada entre los Saxónes y Polácos, se ve una sobérbia Ciudad, llamada Kuniesberg. Esta Ciudád, pues, viene de la parte meridionál a tener un rio llamádo Pregula, en las dos orillas del qual, obra de légua y média antes de la Ciudád, se descubren dos fuentes maravillosas, que rebósan cierto betún unas veces blanco, otras amarillo, o negro, de el qual se conficiona el electro, que vulgarmente llamámos ámbar, porque como el dicho betún descienda por aquel rio, y se engolfe en el mar Germánico, que dista de alli seis millas, ansi por el frio inclemente de aquellas partes que le condensa y aprieta, como por la fuerza del agua marina, que resuelve todo lo vaporóso, y conserva lo gruesso y terrestre: en él viene a empedernecerse del todo, y mudarse como en natúra de piedra, como el crystál con el hielo. Endurecido aqueste liquór en la forma yá declaráda suele ser arrojádo de las impetuossisi- 
mas olas, por todas aquellas costas vecínas, y principalmente por las de la Isla Sudau, la qual antiguamente se llamaba Glesária, por recogerse en ella gran cantidád de este ámbar, a quien tambien llamaron los antíguos por esta causa Gleso, de donde despues se distribuye por todas las Alemanias: lo qual viendo Cornelio Tacito dixo que solos los Tudescos vecínos de aquel mar cogían el verdadéro electro, no obstante que algunos afirman hallarse en minerál en otros lugáres; pero lo cierto es que es betún, y no piedra: su colór es amarillo transparente.

CALDAICA. Piedra semejante al topácio, que se cría en Alemánia, y dicen tiene la virtud de enfriar el agua.

HOJA DE LATA. Cierta plancha de hierro mui delgada, con un colór que le dán como de plata, y sirve para canáles de tejádos, regaderas, alcúzas, embudos y otras cosas. Ya se hace en España y con ventaja a las de Alemánia, cuyo secreto y fabrica se ha conseguido en los tiempos del Rey nuestro señor Phelipe el Quinto deste nombre.

En ninguna de estas voces se hace referencia a la etimología. Alemanisco, de la palabra Alemania, se considera un galicismo. El origen de ámbar se declara incierto en la última edición del DRAE. La información que se ofrece sobre la zona de donde procede el ámbar es detallada. Los académicos hablan de Kuniesberg (en alemán Königsberg, hoy Kaliningrado), fundada por los caballeros de la Orden Teutónica, quienes la convirtieron en la capital de Prusia Oriental en la Baja Edad Media. Fue una importante ciudad portuaria a orillas del Báltico, donde los caballeros teutones comerciaban el ámbar y objetos derivados de la resina vegetal. Este territorio fue objeto de conflictos entre Prusia y Polonia en el siglo XV. Por su parte, la voz caldaico, resulta más misteriosa aún, pues desaparece del diccionario académico por completo y sólo tiene una reaparición en 1936 sin que se apunte la etimología. El caso de hoja de lata, donde los académicos apuntan orgullosos que la calidad de este producto puede competir con Alemania, resulta sorprendente. La voz se recoge en el segundo tomo editado en 1729, cuando la Real Fábrica de Hojas de Lata de San Miguel, en la serranía malagueña de Ronda, apenas cuenta con tres años de existencia, pues en 1726 Felipe $V$ autoriza su puesta en marcha. La fábrica disponía de varios talleres de laminado, hornos, etc., y se convirtió pronto en una industria metalúrgica de gran relevancia para la época. Comenzó su funcionamiento en 1731 bajo la dirección de los suizos Meuron y Dupasquier, a quienes se concedió la exclusiva de fabricación por quince años.

Como ya vimos en la introducción, a finales del siglo XV la política matrimonial de los Reyes Católicos hizo que se establecieran contactos con diferentes naciones de Europa. El más importante de éllos fue el que dió paso en España a la dinastía de los Habsburgo. Citamos la única voz que hemos encontrado, donde se menciona dicha dinastía ${ }^{28}$ :

BELFO. Vale cáido el lábio inferiór, y como curvo: y assi los que tienen el lábio gruesso, y caído hacia la barba se llaman Belfos, como han sido muchos de los Príncipes de la Casa de Austria.

\footnotetext{
${ }^{28}$ El añadido («como han sido muchos de los Príncipes de la Casa de Austria»), se suprimió ya en la revisión del diccionario en 1770 .
} 
Peculiar es el ejemplo de paro $^{29}$, en el que los académicos nos brindan una traducción de la palabra al alemán (e inglés). Se trata del mousebirt o Mausvogel (en inglés y alemán actuales, respectivamente), en español cólido o pájaro ratón, que se cría en África subsahariana:

PARO. Avecilla que está casi siempre en los árboles, y se sustenta de los insectos que encuentra en ellos. Como tambien cañamones y nueces, que las agujéra con su pico, que es mui agudo. Hace su nido en lo que agujéra de los árboles; aunque alguna vez le forma de figura de huevo, dexando al lado un agujerillo por donde entrar. Es mui inquieta, y no sabe estar en lugar fixo, passando de un arbol a otro. El pico es corto; pero mayor que lo que corresponde a su cuerpo, que es pequeñito, y la cola mui larga. Canta mui bien, y pare muchos huevos. Los Ingleses y Alemánes la llaman Mice o ratón porque (como este animál) se pone en los agujéros. Hay muchas especies que se distinguen por sus adjetivos, como Paro mayor, negro, cerúleo, palustre, crestado, sylvático, Indiano, carbonéro, etc.

\section{CONSIDERACIONES FINALES}

En total son 59 las voces que los académicos consideran, con más o menos decisión, de procedencia germánica en el Diccionario de Autoridades, sin contar los derivados. Algunas de ellas vienen avaladas por la autoridad de Covarrubias y otros autores, mientras que el resto viene autorizado por el juicio de la propia Academia.

Los procedimientos para declarar una voz como germánica son dos: acudir a la autoridad lexicográfica de un autor, que por lo general propone un étimo germánico, u ofrecer sin más el étimo germánico ${ }^{30}$; en este segundo caso es la Academia quien asume el papel de autoridad lexicográfica. Respecto a la postura que los académicos adoptan frente a la autoridad lexicográfica de otros autores podemos distinguir tres tipos de juicio:

a) El autor o autores piensan que es germanismo y la Academia concuerda. El hecho de exponer la opinión de un autor ya muestra cierto decantamiento. Como sostiene Seco, «La cita de estas etimologías ya implica una forma de aprobación más o menos decidida» (2003 [1987]: 22). Se trata de las voces: bandera, blanco, daga, danza, ferreruelo, gris, jardín, perla, rico y rocín. Como ya vimos, hay palabras que aunque no mencionen a Covarrubias, es de él de quien procede la información etimológica (véase estaca y estuco).

b) El autor o los autores opinan que es un germanismo y la Academia disiente. Por ejemplo:

LACAYO. Covarr. siente es voz Alemána [...]; pero tambien es verisimil se puede haver tomado del Francés Laquai, que significa lo mismo.

La negación no es rotunda, pues explican: «también es verosimil», sin excluir la primera etimología. A primera vista formarían parte de este grupo aquellas palabras a las que los académicos atribuyen origen latino, en lugar de germánico. No obstante, se puede aplicar a ellas lo que se indica en tregua: «Es voz Theutónica, de donde la tomó

\footnotetext{
${ }^{29}$ El paro que se describe aquí no coincide con el ave que el DRAE describe en la actualidad.

${ }^{30} \mathrm{Se}$ dan algunas excepciones como: baron, escaparate, esmalte, estuche, estufa, jardin, lacayo, robar y tregua, que carecen de étimo.
} 
la baxa Latinidad». De este modo voces como feudo, ganso, camisa o robar, pueden seguir siendo consideradas germanismos.

c) El autor o los autores defienden otra etimología, pero la Academia difiere y lo declara germanismo. Se trata de las voces: bosque, burgo, danzar, estoque, estuche, estufa y tonel.

A veces hay diversas opiniones y la cuestión no queda resuelta, pues la Academia no emite juicio y se limita a exponerlas ${ }^{31}$. También es posible que un mismo autor ofrezca varias posibilidades. Véase: balcón, bando, banquete, barón, escanciar, escarlata, escote, esmalte, fuina, harpa.

Sobre las autoridades literarias cabe hacer una última consideración. Todos los germanismos excepto cuatro (brandemburg, brandis, chamberga (2), paquete) contienen al menos una autoridad literaria. Las citas son variadísimas y abarcan un extenso espectro de autores, que apenas se repiten (hemos contado cincuenta fuentes diferentes). El más citado es Miguel de Cervantes (siete veces), seguido de Francisco de Quevedo y Estebanillo (seis y cinco veces respectivamente). La fuente más antigua es Las Partidas, mientras que las más modernas son la Pragmática de Tassas de 1680 y la Orden Militar de 1728.

Para concluir, ofrecemos el listado de las voces a las que el Diccionario de Autoridades atribuye origen germánico. Quedan exluidos los germanismos latinos, así como también las voces godo, gótico y tudesco, pues en ninguna de ella se indica la etimología. Casi la mitad de estas palabras tienen que ver con relaciones bélicas (moda militar, títulos militares, armadura y armas):

$$
\begin{aligned}
& \text { albergue, bahurrero, balcón, banar, bandera, bando, banquete, barón, bibaro, bi- } \\
& \text { rrete, blanco, bosque, brandemburg, brandis, brecha, brindar, brindis, burgo, } \\
& \text { burgomaestre, camisa, capa, carlanca, daga, danza, danzar, chamberga, dragones } \\
& \text { (3), escanciar, escaparate, escarlata, escote (3), esmalte, estaca, estoque, estuche, } \\
& \text { estuco, estufa, ferreruelo, feudo, fúcar, fuina, gandaya, ganso, gris, harpa, jardin, } \\
& \text { mariscal, marqués, paquete (2), perla, rico, robar, rocín, talco, tonel, trabuco, tre- } \\
& \text { gua, uvaguemaestre, vivac, yelmo. }
\end{aligned}
$$

Con el paso del tiempo, la Academia corregirá algunas de estas etimologías y apuntará en otras «origen incierto». Si bien el tema de las correcciones y modificaciones requiere que se le dedique un estudio aparte.

\section{REFERENCIAS BIBLIOGRÁFICAS}

ALVAR EZQUERRA, Manuel (1993): Lexicografía descriptiva, Barcelona, Biblograf. (2002): De antiguos y nuevos diccionarios del español, Madrid, Arco/Libros.

${ }^{31}$ La voz albergue recoge la opinión de Lypsio, Bossio (palabra Alemana Herbergen), Covarrrubias y Guadix (nombre Arabigo), Diego de Urrea (del verbo Arabigo Berége). Para concluir que «el origen de esta voz es dudoso». 
AZORÍN FERNÁNDEZ, Dolores (2000): Los diccionarios del español en su perspectiva histórica, Alicante, Universidad de Alicante.

Corominas, Joan y José Antonio PASCUAL (1983-1991): Diccionario crítico y etimológico castellano e hispánico, Madrid, Gredos.

COVARRUBIAS, Sebastian de (1943 [1611]): Tesoro de la lengua castellana o española, Madrid-México, Ediciones Turner.

COTARElo Y MORI, Emilio (1914): «La fundación de la Academia Española y su primer director D. Juan Manuel F. Pacheco, Marqués de Villena», Boletín de la Real Academia Española, I, pp 4-38 y 89-127.

FRIES, Dagmar (1989): La Real Academia ante el uso de la lengua. «Limpia, fija y da esplendor», Madrid, SGEL.

GAMILlSCHEG, Ernst (1967): «Germanismos», en Manuel Alvar et al., Enciclopedia lingüistica hispánica, Madrid, CSIC, II, pp. 79-91.

GILI GAYA, Samuel (1963): La lexicografía académica del siglo XVIII, Oviedo, Universidad de Oviedo.

GóMEZ-PABLOS, Beatriz (2014): «Voces y frases relacionadas con Flandes en el Diccionario de Autoridades», Revista de Filología de la Universidad de La Laguna, 32, pp. 209-226.

JIMÉNEZ RÍos, Enrique (2001): Variación léxica y diccionario: Los arcaísmos en el diccionario de la Academia, Madrid-Frankfurt, Iberoamericana-Vervuert.

(2000): «Las autoridades lexicográficas en el Diccionario de Autoridades», en Annick Englebert, Michel Pierrard, Laurence Rosier y Dan van Raemdonck, eds., Actes du XXII Congrès International de Linguistique et de Philologie Romanes, Bruxelles, 2329 juillet 1998, Yübingen, Niemeyer, 4, pp. 317-326.

KÖBLER, Gerhardt (1993): Althochdeutsches Wörterbuch, en http://www.koeblergerhard.de /ahdwbhin.html [consulta 14/02/2014]

(1995): Deutsches etymologisches Wörterbuch, en http://www.koeblergerhard.de /derwbhin.html [consulta 14/02/2014]

LAPESA, Rafael (1981): Historia de la lengua española, Madrid, Gredos.

LÁZARO CARRETER, Fernando (1949): Las ideas lingüísticas en España durante el siglo XVIII, Madrid, CSIC.

- (1980): «El primer diccionario de la Academia», en Estudios de Lingüística, Barcelona, Crítica, pp. 83-148.

Lope BlAnCH, Juan M. (1977): «Sebastián de Covarrubias y el elemento germánico del español», Anuario de Letras, XV, pp. 244-257.

MEDINA Guerra, Antonia M., coord. (2003): Lexicografía española, Barcelona, Ariel.

SECO, Manuel (2003 [1987]): Estudios de lexicografía española, Madrid, Gredos.

SELLÉS-FERRANDO, Xavier (2004): Österreichisches Spanien, Viena, Böhler.

TuÑón DE LARA, Manuel, Julio VALDEÓn BARUQUe y Antonio DOMÍNGUEZ ORTIZ (1991): Historia de España, Barcelona, Labor.

Real ACADEmia Española (1960 [1726-1739]): Diccionario de Autoridades, Madrid, Gredos.

(1991 [1780]): Diccionario de la lengua castellana, Madrid, Gredos.

(2014): Diccionario de la lengua española, Madrid, Espasa. 